\title{
Multimodality in Proximal Deixis in English as a Foreign Language for Technical Presentation
}

\author{
Condra Antoni ${ }^{1}$, Roza Puspita ${ }^{2}$ \\ \{condra@polibatam.ac.id ${ }^{1}$,roza@ polibatam.ac.id $\left.{ }^{2}\right\}$ \\ Politeknik Negeri Batam, Batam, Indonesia ${ }^{1,2}$
}

\begin{abstract}
Using verbal and other modes are inevitable when language is functioned as a device for meaning-making both in native and non-native English communication contexts. This study investigates what modes are used by non-native speakers when using English proximal deictic expressions 'this/these/here' in presenting the technical process of making a brochure as a promotional tool of an Indonesian state Polytechnic profile. A multimodal discourse analysis was employed in this study. The research data were taken from video-recorded presentations of the students of a multimedia study program at an Indonesian polytechnic and annotated using ELAN software. The participants were chosen based on their score of an English readiness assessment provided by a professional third party. It was found that the speakers used the proximal deixis in together with various movements of body parts like fingers, head, palm, and postures. This study also reveals that the use of various modes in the technical process can function as a sign for locating what has been mentioned through verbal discourses, a clarification of the technicalities in the presentation materials, or compensation for certain vocabularies. The relevance of this study to technical English communication competence for students in vocational education context is also discussed.
\end{abstract}

Keywords: Multimodal discourse analysis, Deixis, Technical Communication.

\section{Introduction}

Using multiple modes is inevitable when language is used as a device for meaningmaking in communication [1],[2] and presentation activities in particular. The use of deictic expressions is inextricable since the presentation activities in contemporary technical communication transaction becomes increasingly dependent on technology [3] like visualization through Microsoft PowerPoint and projector tools and deictic, in many cases, requires not only speech but also non-linguistic mode like gesture [4].

The dramatic emergence of digital technology has made the investigation of multimodal phenomena in communication being captured more vividly. Furthermore, the technology enables a more specific domain like technical communication to be one of the most important aspects of human life [5]. Technical communication is defined as "the ability to analyze rhetorical situations, to learn and apply generic conventions intelligently in context, to use 
technologies to speak effectively to diverse audiences and to solve human problems through better communication" [3].

However, a more specific exploration of multimodal communicative needs which bridges academic and professional work is still relatively absent [1]. Therefore, this study can function as filling the gap since we investigated the use of English as a foreign language (EFL) in the higher vocational education context. Students in vocational education need to be aware of the importance of any communicative competence since communication is one of the highest demands by employers of today's workplace [6]. The investigation of proximal deixis in EFL technical presentation in contemporary communication domain is very important for vocational education English teaching and learning in order to prepare polytechnic graduates to be able to deliver the process of making a technical product in English in a better way. At the same time, they also have an ability or competence to use embodied actions properly. The students need technical communication competence because it can determine their career in their future workplace. For this reason, research in multimodal proximal deixis is very relevant.

Multimodal studies inform that the use of diverse modes is not uncommon in representing and communicating meaning in English since many EFL research have increasingly benefitted a lot from such an interdisciplinary field [1]. In this present study, we look at how a variety of modes is orchestrated when using deixis "this/these/here' in EFL technical presentation by underpinning the assumption that presentation in EFL learning can increase the students' practice hour in order to show and practice their English speaking ability. Moreover, this study is expected to shed light on how the polytechnic students' ensembles may support meaningmaking when presenting a technical process in English as a foreign language. Hence, our research question is what are the contributions of multimodal affordance in making a specific meaning to any proximal deixis at the students' presentations?

\section{Theoretical Framework}

Deictic expressions are commonly referred to the use of speech in together with gestures to point objects, locations, or in general, the world around us since the word deixis itself means "pointing" and is originally from Greek [3],[7]. Context plays important roles in understanding deixis. Without context, it will be problematic to distinguish between deixis and common determiner like demonstrative.

English demonstrative pronouns like "this", "there", and adverb of location like "here" and "there" are among the most common deixis for pointing space and location in daily or face-to-face human interaction [8]. Pointing is categorized into manual and gaze [7]. The former is indicated by the use of index finger, arm, and hand when pointing, while the latter is characterized by the use of gaze in such a gesture. Some deictic expressions require gesture while some others do not [4]. In doing so, English language teaching and learning to face new challenges namely the need to pay close attention to any informative resource other than linguistic mode [1] like embodied actions. Successful foreign language learners are very likely to be in line with their appropriate use of gestures together with deictic expressions [9].

Deictic expressions are empirically found to function as reflecting that objects being referred need a resolution or a recognition for a satisfactory final decision in a negotiation talk [10]. It is also revealed that in English for Academic Purpose (EAP) classroom either proximal or distal deixis can reflect the different conceptualization of space between students and the 
teachers [8]. This is to say that deixis is not only essential in human communication but also an important attribute for meaning-making in real life communication contexts.

\section{Method}

We draw our analysis on the use of verbal language together with embodied actions. Discourse coherence plays a pivotal role when analyzing functions of non-verbal modes in shaping the meaning of verbal mode [11]. Therefore, we look at how meanings were made through the interplay between (linguistic) discourse and embodied actions about delivering information about "how to" design brochures. These entail the choices of their colors, fonts, backgrounds, images, logos, and the layouts in general.

\subsection{Participants}

The participants are English non-native speakers, students of a multimedia and networking study program at an Indonesian state polytechnic, and were chosen based on their score of an English readiness assessment provided by a professional and commercial third party. We chose the participants whose scores were relatively higher than others. Based on the assessment, the highest level at the time of English mapping was intermediate. Therefore, we took the recorded data from the intermediate participants. We also considered that non-native speakers of English who make more variety of modes tend to have a higher English competence, while those whose competences are low tend to focus on making use of spoken mode [12]. In annotating the data, we made use of ELAN software [13] so that we can capture more complex multimodal phenomena like co-occurrence of linguistic and other modes in the video-recorded presentations' data.

\subsection{Procedures}

The participants prepared the slides for an English communication subject presentation. They were asked to make a brochure by utilizing their graphic design skill. Once the brochures were finished, they put it into presentation software in a doc or a JPEG format in order to make it easier for the audience to see the brochure visualization. In doing so the students might prepare a verbal script or a highlight in a note in order to structure their presentation. They used a projector when delivering the presentation. Finally, they were asked to fill in an ethical concern form in order to enable the researchers to use their video-recorded presentations for an academic or a scientific purpose legally. The whole process functions as making the presentation to be a well-planned and easy-interpreted communicative event.

\section{Finding and Discussion}

By analyzing verbal discourse and other modes, this study reveals that the students used the proximal deixis in together with various movements of body parts like fingers, head, palm, and postures. This study also reveals that the use of various modes in the technical process can function as a sign for locating what has been mentioned through verbal discourses, a clarification of the technicalities in the presentation materials, or compensation for specific vocabularies. 
As can be seen from Table 1 the speaker used proximal deixis "here" to indicate the location of "headline" which has been mentioned prior to using the deixis. PA located the position by using index finger toward the projector. At the same time, she gazed at the camera indicating that she faced the audience. Finger and gaze as multimodal affordances were used together with linguistic demonstrative "here" in order to make meaning of a type of font of the "headline" in the technical brochure process she explained. Without using non-verbal modes, the audience might not fully understand what kind of "headline" was being discussed because the "headline" itself can mean anything at the upper position of the brochure.

Table 1. Multimodal Proximal Deixis as a Sign for Locating What Has been Mentioned Through Verbal Discourses

\begin{tabular}{lcll}
\hline Speaker & $\begin{array}{c}\text { Visual capture for proximal } \\
\text { deixis }\end{array}$ & \multicolumn{1}{c}{$\begin{array}{c}\text { Proximal deixis } \\
\text { transcript }\end{array}$} & $\begin{array}{c}\text { Embodied action } \\
\text { description }\end{array}$ \\
\hline PA & & $\begin{array}{l}\text { mmm...for the...for the font } \\
\text { itself I use for the headline } \\
\text { in here } \text { I use ee..the name } \\
\text { of the font is swiss Cn BT. }\end{array}$ & $\begin{array}{l}\text { Index finger pointing } \\
\text { back way to the upper } \\
\text { position projector } \\
\text { And then for the color of andience the } \\
\text { the font itself, I use black. }\end{array}$ \\
\hline
\end{tabular}

Table 2 shows a clarification of colorization of the image in the brochure. The use of index finger while employing the proximal deixis "this" does not only indicate still pointing but the finger moved to form a half circle. This functions to draw on the boundary of the black and white colors because these two colors did not appear in the whole brochure but only in some specific areas where the moving finger directed. Therefore, in order to make clear of the areas, he clarified the technicalities of color processing by orchestrating the moving finger with the proximal deixis "this" at a final piece of his utterance.

Table 2. Multimodal Proximal Deixis as a Clarification of the Technicalities in the Presentation Materials

\begin{tabular}{llll}
\hline Speaker & $\begin{array}{c}\text { Visual Capture for } \\
\text { Proximal Deixis }\end{array}$ & \multicolumn{1}{c}{$\begin{array}{c}\text { Proximal Deixis } \\
\text { Transcript }\end{array}$} & $\begin{array}{c}\text { Embodied Action } \\
\text { Description }\end{array}$ \\
\hline \multirow{3}{*}{ MH } & & In color, I am just using like & Index finger pointing \\
& & two color black and white. & toward the picture by \\
& & And grey. Maybe some like & forming a half circle \\
& grey from the text. Why, & \\
& because I think black and \\
& white is ee neutral color. So \\
& it can be combined \\
& by........ not clear] Arabic. \\
& So, ya, like this \\
\hline
\end{tabular}

Table 3 presents compensation for certain vocabularies. The use of proximal deixis "this" together with pointing the object in the picture indicates explaining the real vocabulary that the speaker wants to talk to the audience. When we looked at closely to the video-recorded and the file of his slide, AS used "this" deixis to identify an object in the slide in which the speaker would like to produce the word "a girl picture." The audience may not understand what the speaker intended to explain if he just says "this picture" without touching the specific location on it. Likewise, when MH says "from this to then", pointing gesture plays a significant role in order to compensate the word substituting that "this" and "then". Although 
the sentence construction "from...to" is quite intelligible as it commonly means "a range of starting point and stop of something," a more specific vocabulary is still needed in order to make the audiences understand what kind of "something" is being discussed. If the vocabulary production is absent, the use of multimodal proximal deixis seems to be an alternative solution.

Table 3. Multimodal Proximal Deixis as a Compensation for Certain Vocabularies

\begin{tabular}{ccll}
\hline Speaker & $\begin{array}{c}\text { Visual Capture for } \\
\text { Proximal Deixis }\end{array}$ & $\begin{array}{c}\text { Proximal Deixis } \\
\text { Transcript }\end{array}$ & \multicolumn{1}{c}{$\begin{array}{c}\text { Embodied Action } \\
\text { Description }\end{array}$} \\
\hline AS & $\begin{array}{l}\text { I am using ... I am } \\
\text { Putting this picture, }\end{array}$ & $\begin{array}{l}\text { Hand lifting in a vertical } \\
\text { position and touching the } \\
\text { picture }\end{array}$ \\
MIS & & $\begin{array}{l}\text { from this to then is } \\
\text { 207 so I divide them } \\
\text { into three }\end{array}$ & \\
& & & \\
& &
\end{tabular}

As has been explicated previously, technical processes are delivered by using verbal or linguistic mode, embodied actions, and technology. These three seems to influence the way how English as a foreign language should be seen. Teachers should be aware that English as foreign language learning in contemporary technical communication is in the urgent need of involving verbal language learning, embodied action training, and technological literacy at the same time. This implies that the curriculum and the assessment of technical English subject also need to consider the importance of multimodal affordance as the students' competence. As has been explored in this paper, the verbal mode cannot stand alone. The students produced a set of English expressions in telling the technical aspects of making a brochure using design graphic. At the same time, non-verbal modes were needed to accompany the verbal in order to make the presentations more intelligible for the audience.

Furthermore, there is a potential question raising from the perspective of EFL proficiency namely, do multimodal proximal deictic expressions compensate the notion of technical communicators (engineers, technicians) who are in nature not familiar with the vast variety of vocabularies when presenting something as it does for social communicators (public speakers, politicians, etc.)? In an academic setting, for instance, it is not uncommon to find that English requirement for engineering is relatively lower than social science or humanities, especially in International University student recruitment system. It could be the case that engineering field does not require English communication as intensive as the other two. If it is the case, then technical communicator trainees like polytechnic students, who are presumably dominant in number in the engineering fields, would need more than English proficiency per $s e$ in order to communicate as appropriate and effective as people from social fields.

\section{Conclusion}

This study exemplifies that the use of the variety of modes accompanying deixis indicates the participants' multimodal communicative strategies especially when verbal mode cannot work alone. Multimodal proximal deixis has been shown to be very useful in meaning- 
making especially for vocational education students who are prepared to be technical communicators once they finish their study at polytechnics.

English demonstrative pronouns like "this", "there", and adverb of location like "here" and "there" are among the most common deixis for pointing space and location in daily or face-to-face human interaction [8]. Pointing is categorized into manual and gaze [7]. The former is indicated by the use of index finger, arm, and hand when pointing, while the latter is characterized by the use of gaze in such a gesture. Some deictic expressions require gesture while some others do not [4]. In doing so, English language teaching and learning to face new challenges namely the need to pay close attention to any informative resource other than linguistic mode [1] like embodied actions. Successful foreign language learners are very likely to be in line with their appropriate use of gestures together with deictic expressions [9].

Deictic expressions are empirically found to function as reflecting that objects being referred need a resolution or a recognition for a satisfactory final decision in a negotiation talk [10]. It is also revealed that in English for Academic Purpose (EAP) classroom either proximal or distal deixis can reflect the different conceptualization of space between students and the teachers [8]. This is to say that deixis is not only essential in human communication but also an important attribute for meaning-making in real life communication contexts.

\section{Acknowledgment}

Our gratitude goes to our students who allowed us to use their video-recorded presentation to be our research data.

\section{References}

[1] Early, M., Kendrick, M., and Potts, D.: Multimodality: Out From the Margins of English Language Teaching. TESOL Q., vol. 49, no. 3, pp. 447-460. (2015)

[2] Kress, G.: Multimodal Discourse Analysis. In Gee, J. P. and Handford, M. (Eds.): The Routledge Handbook of Discourse Analysis, pp. 35-50. Routledge, US (2012)

[3] Hill, C.: Deixis and Digital Communication. Word, vol. 57, no. 2-3, pp. 279-302. (2006)

[4] Levinson, S. C.: Deixis. In Horn, L. R. and Ward, G. (Eds.): The Handbook of Pragmatics, pp. 97-121. Blackwell Publishing Ltd., UK (2004)

[5] Kimball, M. A.: The Golden Age of Technical Communication. J. Tech. Writ. Commun., vol. 47, no. 3, pp. 330-358. (2017)

[6] Robles, M. M.: Executive Perceptions of the Top 10 Soft Skills Needed in Today's Workplace. Bus. Commun. Q., vol. 75, no. 4, pp. 453-465. (2012)

[7] Pfeiffer, T.: Understanding multimodal deixis with gaze and gesture in conversational interfaces. Ph.D. Thesis, Bielefeld University, Germany (2010)

[8] Friginal, E., Lee, J. J., Polat, B., and Roberson, A.: Exploring Spoken English Learner Language Using Corpora. Springer International Publishing, Switzerland (2017)

[9] Lin, Y.-L.: Co-occurrence of speech and gestures: A multimodal corpus linguistic approach to intercultural interaction. J. Pragmat., vol. 117, pp. 155-167. (2017)

[10] Glover, K. D.: Proximal and distal deixis in negotiation talk. J. Pragmat., vol. 32, no. 7, pp. 915926. (2000)

[11] Kress, G. and Van Leeuwen, T.: Multimodal Discourse : The Modes and Media of Contemporary Communication. Arnold, UK (2001)

[12] Morell, T., García, M., and Vicent, I. S.: Multimodal Strategies for Effective Academic Presentations in English for Non-native Speakers in 25 Years of Applied Linguistics in Spain: Milestones and Challenges, pp. 557-568. (2008) 
[13] Max Planck Institute for Psycholinguistics, "ELAN (Version 5.2) [Computer software]," Nijmegen: Max Planck Institute for Psycholinguistics, 2018. [Online]. Available: https://tla.mpi.nl/tools/tla-tools/elan/. [Accessed: 26-Jun-2018] 